\title{
Taking a Book Off the Shelf in a Virtual Library
}

\author{
Sally Jo Cunningham, Bill Rogers, Jane Kim \\ Computer Science Department \\ The University of Waikato \\ Hamilton, New Zealand \\ sallyjo@waikato.ac.nz
}

\begin{abstract}
We present the results of a small-scale study in which participants interacted with a physical book. Their book selection and book opening gestures provide design insights for the interface to a virtual reality library.
\end{abstract}

Keywords-digital library, book selection, human computer interaction, interactive retrieval.

\section{INTRODUCTION \& RELATED WORK}

A number of projects have worked to bridge the differences between real and digital libraries. Christoffel and Schmidt [6] used a 3D game engine to model a library, from buildings to books on shelves. Their system allowed navigation and book selection. Almeida, Cubaud et al [4, 5] built systems with dual displays: a projected hemispherical display showing many bookshelves; and a smaller higher resolution display showing book contents. Book selection was supported with a zoomed in pop-up window showing an individual shelf area. Books could be 'opened' as turnable pages on tripod displays. More realistic virtual books, depicted laying on a table surface, were developed by Angeletaki et al[7] and Lorenzini et al[8]. Their system supported page turning. A more sophisticated book visualization was developed by $\mathrm{Chu}$ et al [9]. In their work, pages realistically bent as they were turned.

These prototype systems have explored the capabilities required for an immersive virtual library, but none are complete: they were limited by hardware in storage capacity, interaction and display. Recent technology developments make it timely to revisit the problem. In particular, we have better resolution headsets with lowered latency on movement and a variety of hand controller devices. It is feasible now to store and access a large number of complete book images in high resolution in real time.

Our project is working towards an immersive library environment with focus on browsing. Specifically, we want to bring together book selection and reading in a smooth immersive manner. Using the HTC Vive virtual reality system and headset, and the Unreal Engine 4 game engine, we have built a bookshelf and populated it with an interestingly varied, realistically depicted set of books. In picking up a book, in the current implementation the user reaches into the shelf and presses the trigger on the controller to 'grip' the book. The book then moves with the hand, and can be turned for closer examination. The question we now face is: how does the user get from this point to browsing the text of the book? We seek to design an interface mechanism to cover this transition from grabbing to viewing a book.
Other researchers have looked at shelf browsing and book interaction behavior in real libraries. In [2] Reutzel watched children selecting books to read. The most common behavior was to pull the book out and flip through the pages to view content. In [1] Hinze, et al. observed patrons in academic libraries. Typically they pulled out a book by tilting it with a finger on the top, grabbed it and began to flip through. The book might be held in the left or right hand and could be flicked in forward or reverse page order. However, the progression from pulling a book from a shelf to opening and browsing it was not recorded in either experiment. To better understand that process we designed a focused lab experiment

\section{Methodology}

Participants were asked to stand in front of a bookshelf, select a particular book (Web Dragons), locate Chapter 4 in the book, and read out loud the chapter title and first sentence. The target book was positioned near the center of a fairly full shelf, and the shelf was $120 \mathrm{~cm}$ from the ground (and so not quite at eye level for participants, but still within easy sight and reach). We note that previous 3D digital library and realistic book simulations have modeled a book as having a hard, inflexible cover (perhaps to simulate 'serious' - that is, hardback-books found in academic libraries). Earlier observational studies [1-2] involved hardback books as well. Web Dragons is a trade softback, chosen to see whether additional behaviors were used with softback books.

Each session was video recorded. The average time to complete the task was 48 seconds (minimum 30 seconds, maximum 86 seconds). Thirty participants were recruited: 20 male and 10 female, and 27 right-handed and 3 left-handed. Their age distribution was: $17-20$ years old, $15 ; 21-30$ years, $10 ; 31-40$ years, $1 ; 41-50$ years, 2 ; and $51-60$ years, 2 .

\section{RESUlTS \& DisCUSSION}

To find the target book, the participants first positioned themselves within a comfortable reaching distance of the bookcase. 7 of the 30 participants ran a hand along the shelf, either in front of or actually touching the books or shelf, as they linearly scanned for the correct book. All participants used a single hand to pull the book from the shelf, favoring their dominant hand by a roughly $2: 1$ ratio (18 of the 30 participants used their dominant hand). 

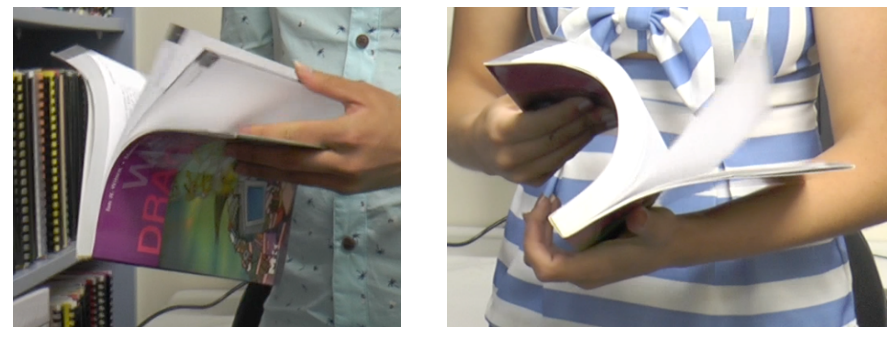

Fig. 1. (a) Holding book in both hands \& (b) Holding spine in palm

When grasping the book on the shelf, 8 participants pulled it out by the top of the spine, 2 by the bottom of the spine, and 16 by the middle. 4 participants shifted their hand on the spine as they pulled: 1 from the top to the bottom, and 3 from the top to the middle.

Once the book was completely away from the shelf, the next activity was to move the book into a comfortable position in order to find Chapter 4. 5 participants made two or more shifts in book position before settling on a stable book holding position. As they looked for Chapter 4, 14 participants supported the book with the same hand with which they pulled the book from the shelves, 7 transferred the book to the opposite hand to hold, and 9 held the book with both hands (grasping it by the edges of the pages; Fig. 1a). The 21 participants who held the book primarily with one hand either balanced the spine (Fig. 1b) or the back cover of the book (Fig. 2 ) in the palm of one hand, perhaps with part of the cover resting on their forearm.

To locate Chapter 4, 21 participants immediately began flipping/riffling through the book's pages and the remaining 9 first consulted the Table of Contents before flipping to locate Chapter 4 . The initial direction for flipping or riffling was forwards through the book for 20 participants and backwards for 10. 18 participants "overshot" as they flipped (some by a considerable margin and some only by a page or two); of these 18, 14 changed the direction in which they flipped after the overshot

\section{CONCLUSIONS}

Although the results show quite an amount of variation the most popular process was: grasp a book with dominant hand; turn the book over in the same hand; hold it balanced on the spine; use the other hand to rifle the pages. The most common variants are using the non-dominant hand and swapping from hand to hand. This pattern appears suitable, with small adaptation, for use with the controller in the virtual reality system. Initial grasping can be simple. Detail, like pulling the book out with a finger is not possible as we do not have individual finger input, but fortunately is not necessary in the virtual environment, as a hand can pass through the books on either side to grab directly. As the system has two controllers, the user can be allowed to use either hand; there need be no concept of dominant hand in the implementation, so the user can be free to use whichever hand they please. Passing from hand to hand is possible in our prototype, although a little awkward - the user grabs with one hand and lets go with the other.

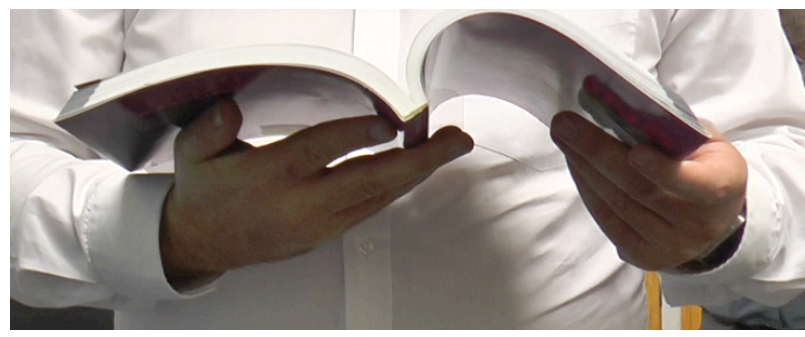

Fig. 2. Resting back cover on hand/forearm

While an unexpected behavior was supported by the flexible softbound book - grasping the edges of the book with both hands while flipping - this behavior cannot be easily supported with the controllers and so we will follow convention and simulate hardcover books.

Turning the book over and balancing (rather than grasping) it, translates to a very clear, easily captured gesture - turn the controller over and let go of the trigger. The hand is left in a comfortable position, 'supporting' the book. Letting go of the trigger is not essential but would contribute to user comfort. The page flipping process can be directed using the hand (controller) that is not supporting the book. Holding the hand just above or below the book and moving left and right to control direction and rate of flipping seems practicable. This is not as direct a manipulation of the book as one might have hoped for, but it does have the advantage of allowing users to minimize, or at least quickly correct for, the overshoot that was commonly observed in the experiment

\section{REFERENCES}

[1] Hinze, A., McKay, D., Vanderschantz, N., Timpany, C., \& Cunningham, S. J. 2012. "Book selection behavior in the physical library: implications for ebook collections". JCDL'12, 305-314.

[2] Reutzel, D. R., \& Gali, K. 1998. "The art of children's book selection: A labyrinth unexplored". Reading Psychology, 19(1), 3-50.

[3] Witten, I. H., Gori, M., \& Numerico, T. 2010. Web dragons: inside the myths of search engine technology. Elsevier.

[4] Cubaud, P., Stokowski, P., Topol. R. 2002. "Binding browsing and reading activities in a $3 \mathrm{D}^{-}$digital library". $J C D L$ ' $02,281-282$.

[5] Almeida, R., Cubaud, P., Dupire, J., Natkin, S., \& Topol, A. 2006 "Experiments towards 3D immersive interaction for digital libraries". International Conference on Technologies for E-Learning and Digital Entertainment, 1348-1357).

[6] Christoffel M., Schmitt B. 2002. "Accessing libraries as easy as a game”. In: Börner K., Chen C. (eds) Visual Interfaces to Digital Libraries. Lecture Notes in Computer Science, vol 2539. Springer, Berlin, Heidelberg

[7] Angelataki, A., Carrozzino, M., Johansen, S. 2014. MUBIL: "Creating $3 \mathrm{D}$ experience of 'reading books' in a virtual library laboratory". Int Journal of Heritage in the Digital Era, Vol 3, Issue 2, 271-286

[8] Lorenzini, C., Evangelista, C., Carrozzino, M., Postelnicu, C., \& Maltese, M. 2016. "An interactive digital storytelling approach to explore books in virtual environments". Informatica, 40(3).

[9] Yi-Chun Chu, D. Bainbridge, M. Jones and I. H. Witten. 2004 "Realistic books: a bizarre homage to an obsolete medium?" JCDL'04, 78-86. 